The University of Southern Mississippi

The Aquila Digital Community

Student Publications

$2-2018$

\title{
No More Reason For Ignoring Gelatinous Zooplankton In Ecosystem Assessment and Marine Management: Concrete Cost- Effective Methodology During Routine Fishery Trawl Surveys
}

\author{
A. Aubert \\ National Museum of Natural History, anais.aubert.aa14@gmail.com \\ E. Antajan \\ IFREMER, Channel and North Sea Fisheries \\ C. Lynam \\ The Centre for Environment, Fisheries and Aquaculture Science \\ S. Pitois \\ The Centre for Environment, Fisheries and Aquaculture Science \\ A. Pliru \\ University of Southern Mississippi
}

See next page for additional authors

Follow this and additional works at: https://aquila.usm.edu/student_pubs

Part of the Marine Biology Commons

\section{Recommended Citation}

Aubert, A.; Antajan, E.; Lynam, C.; Pitois, S.; Pliru, A.; Vaz, S.; and Thibault, D., "No More Reason For Ignoring Gelatinous Zooplankton In Ecosystem Assessment and Marine Management: Concrete Cost-Effective Methodology During Routine Fishery Trawl Surveys" (2018). Student Publications. 46.

https://aquila.usm.edu/student_pubs/46

This Article is brought to you for free and open access by The Aquila Digital Community. It has been accepted for inclusion in Student Publications by an authorized administrator of The Aquila Digital Community. For more information, please contact Joshua.Cromwell@usm.edu. 
Authors

A. Aubert, E. Antajan, C. Lynam, S. Pitois, A. Pliru, S. Vaz, and D. Thibault

This article is available at The Aquila Digital Community: https://aquila.usm.edu/student_pubs/46 


\title{
No more reason for ignoring gelatinous zooplankton in ecosystem assessment and marine management: Concrete cost-effective methodology during routine fishery trawl surveys
}

Aubert Anaïs ${ }^{1,{ }^{*}}$, Antajan Elvire ${ }^{2}$, Lynam Christopher ${ }^{3}$, Pitois Sophie ${ }^{3}$, Pliru Antonio ${ }^{4}$, Vaz Sandrine ${ }^{5}$, Thibault Delphine ${ }^{6}$

${ }^{1}$ National Museum of Natural History (MNHN), CRESCO, 38 Rue du Port Blanc, F-35800 Dinard, France

2 IFREMER, Channel and North Sea Fisheries Research Unit, 150 quai Gambetta, F-62321 Boulognesur-Mer, France

${ }^{3}$ The Centre for Environment, Fisheries and Aquaculture Science (CEFAS), Pakefield road, Lowestoft NR33 ORP, UK

${ }^{4}$ University of Southern Mississippi, Department of Marine Science, 1020 Balch blvd., Stennis Space Center, Mississippi, MS 39529, USA

${ }^{5}$ IFREMER, UMR MARBEC, Avenue Jean Monnet, CS 30171, 34203 Sète Cedex, France

${ }^{6}$ Aix-Marseille University, CNRS/INSU, Université de Toulon, IRD, Mediterranean Institute of Oceanography (MIO), UM 110, 13288 Marseille, France

* Corresponding author : Anaïs Aubert, email address : anais.aubert.aa14@gmail.com

\begin{abstract}
:
Gelatinous zooplankton, including cnidarians, ctenophores, and tunicates (appendicularians, pyrosomes, salps and doliolids), are often overlooked by scientific studies, ecosystem assessments and at a management level. Despite the important economic consequences that they can have on human activities and on the marine foodweb, arguments often related to the costs of monitoring or their coordination, or simply negligence, have resulted in the absence of relevant monitoring programs. A cost-effective protocol has been applied on trawling from existing fishery surveys conducted by national laboratories in England and France. The testing phase has successfully demonstrated the adequacy of such a tool to sample macro- and mega-zooplankton gelatinous organisms in a cost-effective way. This success has led to the acceptance of this protocol into the French implementation of the EU's Marine Strategy Framework Directive (MSFD). Here, a protocol which can be applied to any trawl-based fishery survey and in any new large-scale monitoring program is provided. As an ecosystem approach to marine management is currently adopted, exemplified by the MSFD in Europe, gelatinous zooplankton should be monitored correctly to prevent a knowledge gap and bias to ecosystem assessments in future.
\end{abstract}




\section{Highlights}

- There is a clear gap in the monitoring of macro- and mega- gelatinous zooplankton. A costefficient method taking advantage of fish trawling has been successfully tested. A step by step protocol to record the bycatch of gelatinous zooplankton is provided here. Gelatinous zooplankton should be considered in ecosystem based marine management.

Keywords : Gelatinous zooplankton, Jellyfish, Monitoring, Trawl, Marine management, MSFD 


\section{$1 \quad 1$ Introduction}

Gelatinous zooplankton (GZ) is comprised by species, with a planktonic stage (living in the water column) and characterized by a gelatinous body, of the phyla Cnidaria (classes Scyphozoa, Cubozoa, Hydrozoa and Staurozoa; with the term jellyfish comprising the first three classes), Ctenophora (classes Nuda and Tentaculata) and Chordata (class Appendicularia and Thaliacea). GZ are widely known for their amazing shape and colors, and due to their formation of dense aggregations ("blooms") along coasts during spring and summer seasons and subsequent human health and economic consequences [1, 2, 3]. GZ are also of great importance as food for other animals including humans, and have potential medical applications. Nevertheless, their detrimental effects on tourism can be particularly important. For example, along the Salento coastline in Italy, first-aid services due to jellyfish stings reached a direct cost of 400,000 euros over a 5-year period [4]. Jellyfish aggregations became so common in the area that one wonders whether the coming year will be a "jellyfish year". Oscillations in frequency of GZ blooms of 10-15 years [5] have been reported in the northwest Atlantic, but the current knowledge does not allow to effectively predict their seasonal onset and geographical dynamics. Behind this lack of information is a clear absence of long-term data sets $[6,7,8]$.

Current GZ data collection activities are usually designed for specific short-term projects [9], or through citizen science initiatives (e.g. Marine Conservation Society of the UK jellyfish survey, JellyWatch, JellyRisk...) and only in rare instances are they included in national monitoring programs. As a result, the data available are generally scarce in terms of spatial and temporal coverage and often of limited use. Moreover, data collected near shore do not necessarily reflect the processes occurring offshore [10], and this constrains the potential ability to understand population dynamics. Beyond the jellyfish group, whose stinging cells have harmful effects on economic activities (fisheries, tourism), other GZ such as ctenophore or salp differ greatly in terms of morphology, phylogeny, biology, and physiology [11]. The lack of data on those organisms is detrimental to our understanding of ecosystem functioning and their role has been neglected, including in trophic models where they are often wrongly depicted as trophic dead-ends [12].

GZ have the potential to impact marine food webs at multiple levels. Predatory jellyfish and ctenophores often feed on both the same prey items as planktivorous forage fish and the juvenile stages of piscivorous ones $[1,13]$ having, thus, the potential to adversely impact fish recruitment through competition and predation $[14,15,16]$. In the most extreme case scenario, where high fishing pressure results in the collapse of fish stocks, newly available ecological niches could become occupied by jellyfish. 
Jellyfish then, exerting top-down control on zooplankton to primary producers further reduces the availability of prey items for the depleted fish stocks (also known as the jellyfish 'joyride') [18, 19] implying important economic repercussions on weakened fisheries. As clear examples, the northern Benguela off Namibia and the Black Sea used to support abundant commercial fish stocks, which following overexploitation became fish-poor and dominated by $\mathrm{GZ}[20,21]$. In addition, numerous short-term and direct economic impacts of extensive aggregations of GZ have been reported worldwide, such as: clogging of fishery nets, aquaculture fish mortality, or obstruction of cooling systems of coastal desalination, nuclear and coal-fired power plants [22]. It has been also shown that jellyfish polyps can fix on artificial structures at sea, thus coastline development will provide more surface for settling of polyps [23].

A better understanding of the population dynamics of GZ and socio-economic effects would allow management measures to be implemented to prevent or mitigate their impacts (adaptation rather than transformational governance strategies, cf. [22]). Improved spatial planning of coastal development or the implementation of a tool to predict the risk of high jellyfish abundance on tourist beaches are examples of such management measures. Within ecosystem based management and assessment, indicators of ecosystem instability, could be developed based on GZ data since their populations have been shown to rise rapidly following disturbance $[17,22]$. GZ do not however only represent negative impacts for ecosystems services. Jellyfish as a commercial food already supports an important market in Asia, which is likely to develop in other parts of the world [22]. Medical advances have also been made using some GZ components (i.e. collagen, qniumucin) and new applications have been discovered, such as the potential use of GZ mucus for nanoparticles depollution [24]. Improved ability to predict GZ population dynamics and distribution would also allow for the successful management of new economic resources. GZ also play a key ecological role in the marine ecosystem: they have been shown to represent an important food supply for key fish species such as blue fin tuna, in the western Mediterranean [25], as well as for spiny dogfish and benthic scavengers [26]; they can transfer nutriments to the benthos through the production of large fecal pellets [27], or through decomposition of jellyfish, particularly following a blooming event [28]; they can also provide shelters for small fish from predation by larger species [20] and can act as drifting carriers for several crustaceans and anemones. Whether having a detrimental or a positive impact on marine ecosystems and the services they provide, GZ should be included in research and monitoring.

Following the adoption of suitable monitoring of $\mathrm{GZ}$, indicators should be developed that reflect the food web role of $\mathrm{GZ}$ and inform ecosystem assessments such as those required by the Marine Strategy Framework Directive (MSFD) in Europe [29] or the Ecosystem Status Report in North America [30]. Previously, there has been concern by policy makers and managers that even if GZ are monitored, their 
populations are unmanageable, so scarce monetary resources would be better spent on other monitoring. Monitoring for GZ must be thus of minimal cost and ideally be coordinated with current fisheries surveys. So far, very few cost-effective monitoring methods that can cover broad spatial coverage and replicate the effort over time have been developed for GZ, either for scientific or management purposes [8]. There is therefore a necessity to implement a methodological approach to enable such monitoring $[31,32,8]$. Monitoring should rely on internationally standardized approaches which would allow for quality assurance and for comparisons across surveys. It will give the opportunity to the scientific community to estimate and model the spatio-temporal distribution of GZ across large marine ecosystems in a way that has not been possible previously [33,34]. Ideally, GZ data should be obtained from surveys with dedicated plankton sampling in place, which is the case for the Irish Sea Young Fish Survey and the quarter 1 International Bottom Trawl Survey of the North Sea in which GZ are caught using a midwater ring net (MIK net), a standard gear for sampling fish larvae $[17,35]$. However, the deployment of these nets requires specific logistics, and dedicated staff on board. Trawl surveys targeting adult fish using pelagic trawls [14], demersal trawls [36, 37] and even beam trawls [38] have been found to catch large GZ in abundance, allowing for the most notable work on jellyfish dynamics [8]. Consequently, it has been recommended that GZ should be routinely monitored on fisheries surveys [8]. This is particularly promising because data could be acquired with high spatio-temporal coverage and following standardized practices [35].

There is currently no clear protocol for GZ in the scientific literature, which is mandatory if one wants to expand monitoring to fishery surveys in an orderly manner. The heavy reliance by EU Member States on previously developed monitoring programs meant that GZ were not monitored in many areas. Fortunately, project (such as DEVOTES, DEVelopment Of innovative Tools for understanding marine biodiversity and assessing good Environmental Status) and government funding have supported some scientists to test the ability of fishing nets to sample GZ on current scientific surveys. Based on trawling carried out by Cefas (UK) and by Ifremer (France), a robust protocol for GZ monitoring on routine fisheries surveys has been tested since 2012 and 2014 respectively and is proposed here. This protocol has been officially implemented in the MSFD monitoring program in France since 2017. The resulting methodology for monitoring mega- and macro- gelatinous organisms is detailed here. The goal of the present paper is: 1) To raise stakeholder awareness, at the political, scientific and management level, for the need of GZ monitoring, 2) to provide a clear protocol, based on a successful trial phase, that can be directly used during similar fishery surveys using fish trawling and 3) to open the discussion for adopting a harmonized GZ data production in the frame of large scale efficient monitoring. 


\section{Main comments on the protocol and its testing phase}

The full step-protocol provided here (supplementary material 1) should be laminated for use at sea. This protocol has been tested and improved through the testing phase during several fishery surveys within the English and the French EEZ (Exclusive Economic Zone) by Cefas and Ifremer respectively (cf. Table 1).

Table 1. Details of the different fishery surveys in UK and France for the testing of the GZ protocol. The geographical scope is given according to the large regions considered within the Marine Strategy Framework Directive (MSFD). Numbers marked with an asterisk $\left({ }^{*}\right)$ indicate that the protocol has not been entirely tested or not tested for the whole fishery survey of consideration.

\begin{tabular}{|c|c|c|c|c|c|}
\hline Survey & Institute & Year & Dates & $\begin{array}{c}\text { Geographical } \\
\text { scope }\end{array}$ & $\begin{array}{c}\text { Number of gelatinous } \\
\text { occurrence/number of trawls }\end{array}$ \\
\hline \multirow[t]{3}{*}{ IBTS UK Q3 } & Cefas & 2012 & $\begin{array}{l}08 / 08-07 / 09 \\
03 / 08-31 / 08\end{array}$ & $\begin{array}{l}\text { English Channel } \\
\text { and North Sea }\end{array}$ & $\begin{array}{l}51 / 77 \\
84 / 89\end{array}$ \\
\hline & & 2014 & 07/08-03/09 & & $67 / 73$ \\
\hline & & 2015 & 08/08-05/09 & & $69 / 73$ \\
\hline \multirow[t]{2}{*}{$\begin{array}{l}\text { IBTS FR Q1 } \\
\text { [39] }\end{array}$} & Ifremer & 2015 & $10 / 01-25 / 01$ & $\begin{array}{l}\text { English Channel } \\
\text { and North Sea }\end{array}$ & $12 / 90$ \\
\hline & & 2016 & $21 / 01-19 / 02$ & & $9 / 91$ \\
\hline CGFS & Ifremer & 2015 & $24 / 09-14 / 10$ & English Channel & $22 / 91$ \\
\hline
\end{tabular}

[40]

$2016 \quad 24 / 09-08 / 10 \quad 47 / 73$

$\begin{array}{lcccc}\text { EVHOE } & \text { Ifremer } & 2014 & 02 / 11-01 / 12 & \begin{array}{c}\text { Bay of Biscay and } \\ \text { Celtic Seas }\end{array} \\ \text { [41] } & 18 / 11-01 / 12 & \text { 89/156 }\end{array}$

2015 


\begin{tabular}{|c|c|c|c|c|c|}
\hline \multirow[t]{2}{*}{ [42] } & Ifremer & 2015 & $29 / 04-02 / 06$ & $\begin{array}{c}\text { Bay of Biscay and } \\
\text { Celtic Seas }\end{array}$ & $17 / 25 *$ \\
\hline & & 2016 & 02/05 -31/05 & & $46 / 149$ \\
\hline MEDITS & Ifremer & 2015 & $22 / 05-27 / 06$ & Western & $54 / 88$ \\
\hline [43] & & 2016 & $21 / 05-24 / 06$ & $\begin{array}{l}\text { Mediterranean } \\
\text { Sea (Gulf of Lion } \\
\text { and Corsica) }\end{array}$ & $61 / 87$ \\
\hline PELMED & Ifremer & 2015 & $28 / 06-02 / 08$ & Western & $6 / 52 *$ \\
\hline \multirow[t]{2}{*}{ [44] } & & & & $\begin{array}{l}\text { Mediterranean } \\
\text { Sea (Gulf of Lion) }\end{array}$ & \\
\hline & & 2016 & 26/06-31/07 & & $23 / 56$ \\
\hline
\end{tabular}

107

108

109

110

11

11

11

114

115

Trawling positions where GZ were recorded are presented in Fig. 1. The testing phase within the French marine waters was implemented from 2014 to 2016 as part of the French implementation of the Marine Strategy Framework Directive, and from 2012 to 2015 within the English contribution to the quarter 3 International Bottom Trawl Survey. Both testing phases in English and French waters relied on existing fishery cruises and had to be adapted to fit within the ongoing fishery tasks without increasing significantly workload both in terms of time and human resources. 


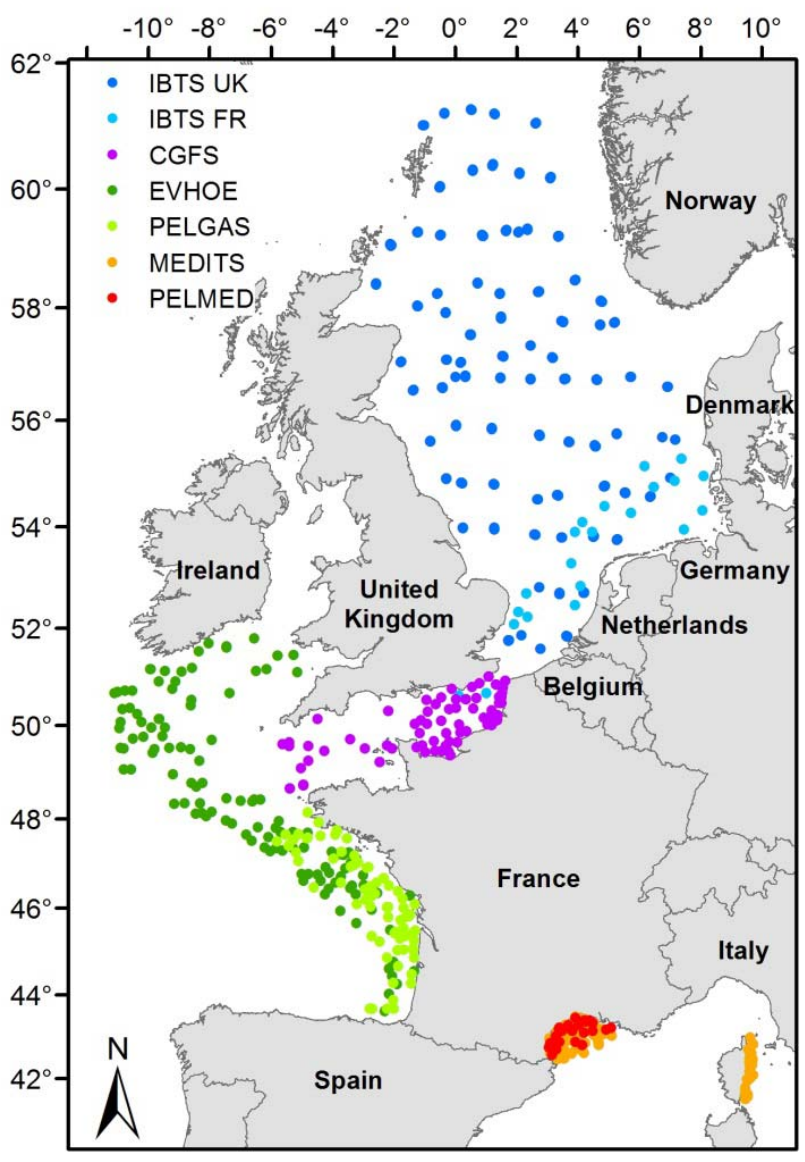

Figure 1. Location of stations where GZ organisms have been encountered with the present protocol for the different fishery surveys (IBTS: International Bottom Trawl Survey; CGFS: Channel GroundFish Survey; EVHOE: Evaluation Halieutique de l'Ouest de l'Europe; PELGAS: Oceanographic Pelagic Gascogne Survey; MEDITS: International bottom trawl survey in the Mediterranean Sea and PELMED: Pelagic Mediterranean survey).

To limit additional work for the implementation of the GZ protocol on existing fishery surveys, the proposed methodology is very similar to that used routinely for fish. For instance, at first volume of GZ was used as a proxy for biomass, but sea conditions, amount of GZ being at time very large and, adjustment to the fish tasks, required to switch to weight measurements. The list of basic equipment required is given in Table 2. Gloves should always be worn, and arms should be covered since all jellyfish species sting to some extent, even when dead. Glasses should be also used as a precaution during handling. 
133 Table 2. Equipment required on board for the GZ protocol implementation

List of equipment required on board
Gloves $\checkmark$
Glasses
Paper
Containers (e.g. $60 * 30 \mathrm{~cm}$ in plastic)
Weighting scale $\checkmark$
Fish ruler $\checkmark$
Plastic rulers (15 cm) $\checkmark$
Camera $\checkmark$
Steps-protocol sheet (laminated) $\checkmark$

A list of GZ taxa with abbreviation codes as well as an identification manual should be provided for each specific region, in addition to the protocol. Although the identification of macro- and mega- GZ does not require specific skills, GZ species are often unknown by the specialist fishery staff so they should familiarize themselves with the identification manual. Particularly, pictures of GZ in and out of the water need to be presented since the organisms appear quite different in the two states. Examples of pictures of organisms out of the water are shown in Fig. 2. 
a.

0616263646566676869707172737475767778798081828384858687888990919295949596979699 m

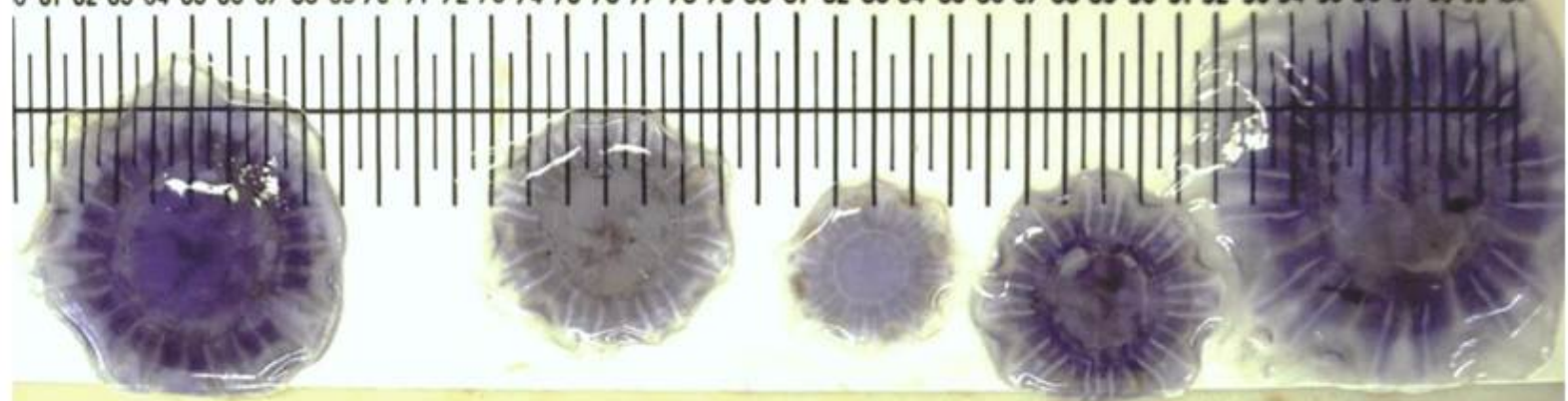

By Ancïs Aubert/IFREMER/PELGAS 2015

(i) (5) creative
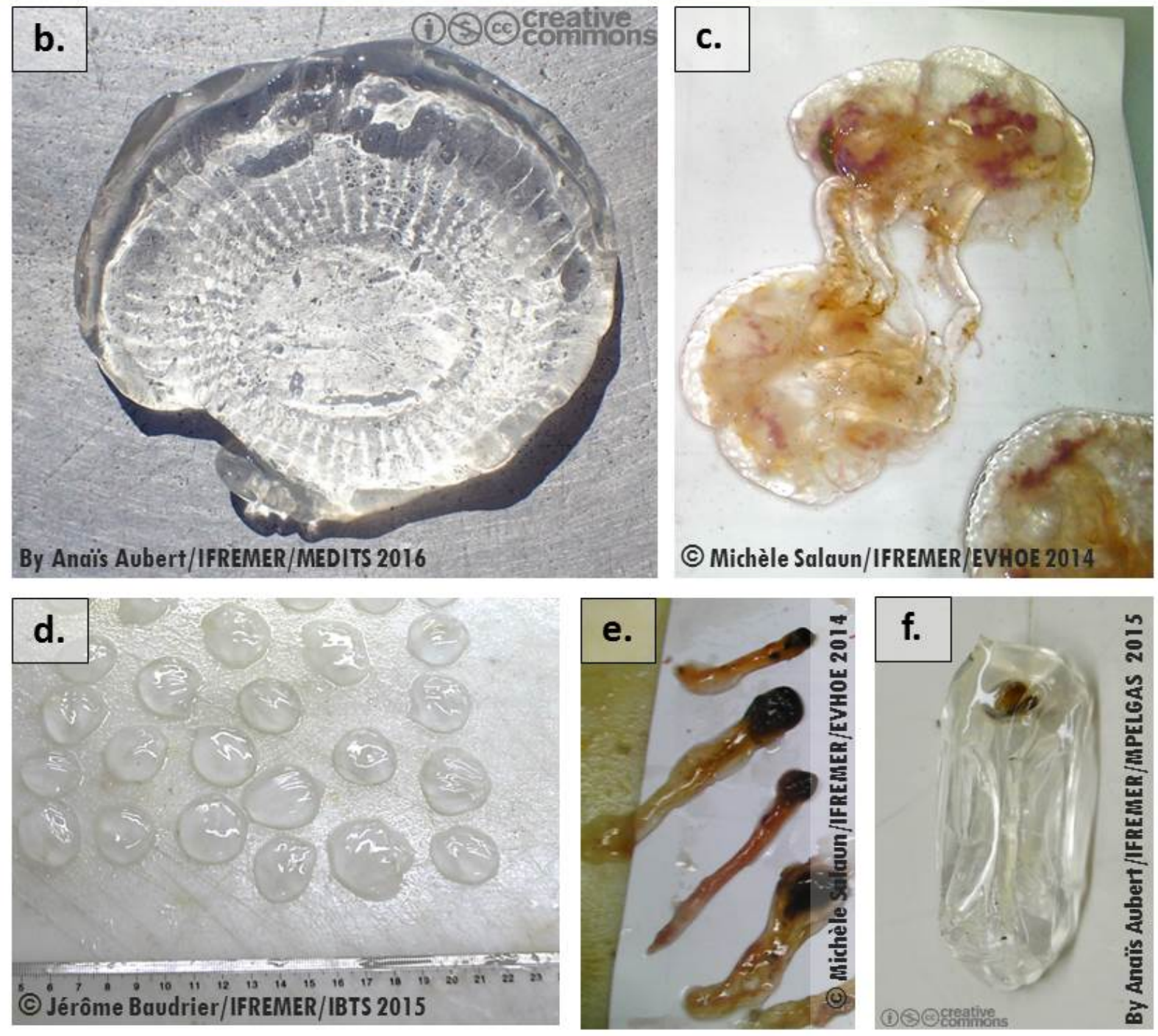

Figure 2. Pictures "out-of-water" of common GZ organisms encountered through the trial phase on fishery surveys. a. Cyanea lamarckii (cnidarian), b. Aequorea forskalea (cnidarian), c. Pelagia noctiluca (cnidarian), specie of salp, well recognizable). 
Basic information such as stinging strength, geographical distribution and main characteristics should be provided in the identification manual as well (cf. identification guide made for the French MSFD as an example, [45]). The checklist of the species/categories found in the French and English marine waters is also provided as an example (supplementary material 2). These types of manuals must be laminated, as done for the protocol sheet, for their use on board during the sorting steps.

The main improvements made to the protocol during the French testing phase (using a data entry software feeding into an official database, which is not the case for the UK GZ monitoring) concerned the taxa categories at different level of identification (Fig. 3).

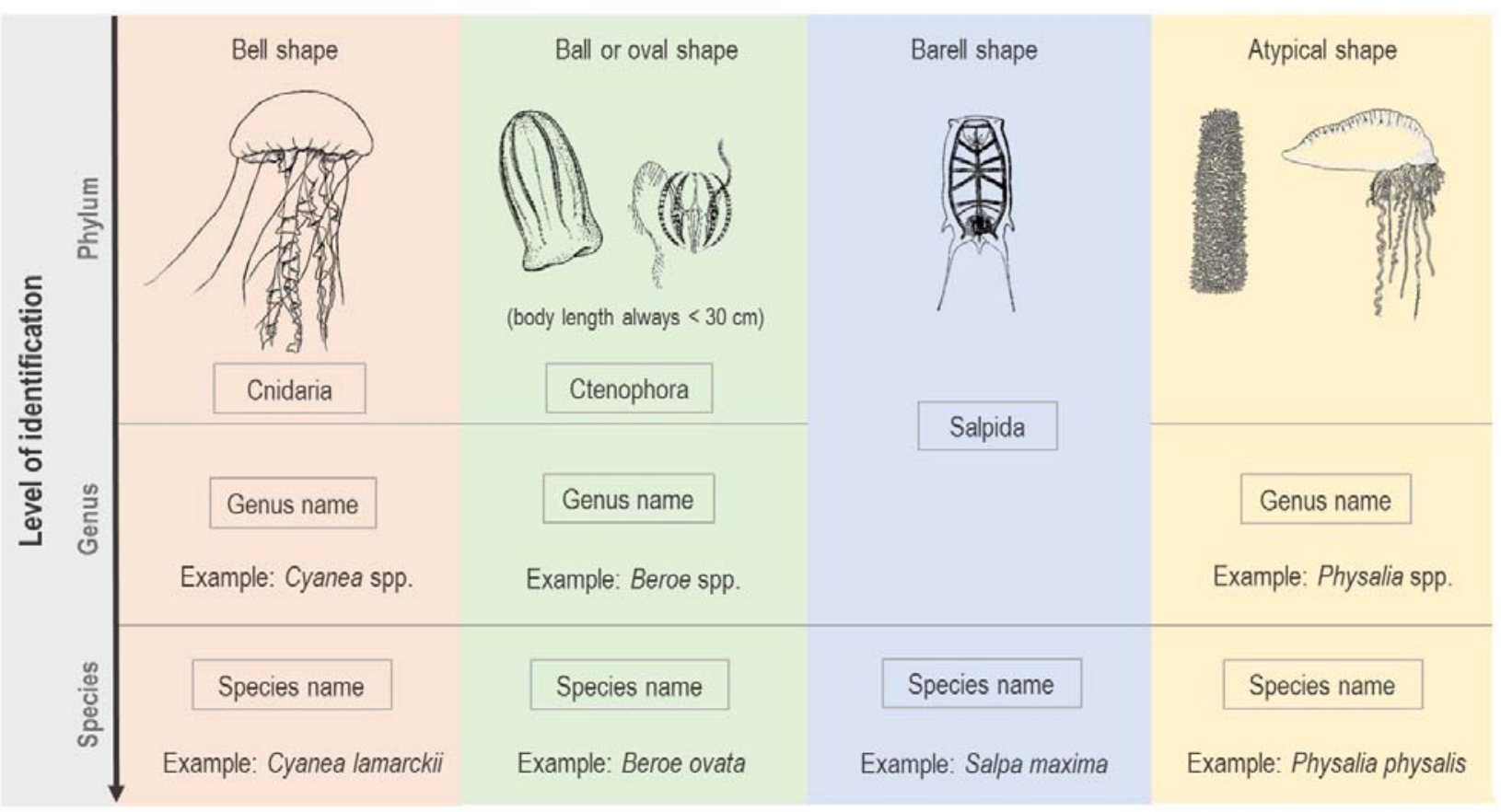

Figure 3. Classification of GZ into four large shape groups. The determination of organisms should be done down to the species level when possible.

An "unidentified" category was initially created for species in good state that could not be determined on board and required later identification and/or validation by expert (pictures-based). However, "unidentified", or other such temporary codes, can no longer be used when fishery data are imported into official databases and they also introduce bias in the database in the long-term. The testing of the present protocol concluded that these non-identified categories should be added as comments, in a specific comment box, related to the specific trawl number. They should be however treated as the other GZ taxa concerning the protocol steps (enumeration, weighing, and length measurements). An example of pictures and information to be noted for a non-identified species is provided on the last page of the step- 
protocol sheet (supplementary material 1). During the protocol testing, a specific category was also created for the organisms found in such a bad state that they cannot be identified to any level. This category has been erased for the same reasons than the non-identified species category. It has been decided to use the taxa "Cnidaria" and/or "Salpa" for all the GZ organisms in too bad state to be determined (the presence of the nucleus of salps will indicate if a gelatinous mass is constituted mostly of salps for instance).

It appeared, during the trial phase, important to include specific information on the trawl (i.e. trawl type, duration of trawl (including net deployment/retrieval and net opening time), boat speed, and maximum sampling depth)) (Table 3). These are essential to convert counts or mass into densities (ind $\mathrm{km}^{-}$ ${ }^{2}$ ) or biomass $\left(\mathrm{kg} \mathrm{km}^{-2}\right)$ of GZ. The surface or volume sampled by a fish trawl is in fact estimated from the aperture of the net and the trawled distance. There is still no common acceptance on how sampled volume in the case of $\mathrm{GZ}$ should be estimated and this will be discussed further in this paper.

The goal of the proposed methodology is to ensure data acquisition consistency across surveys by operating a standardized protocol. It will allow the comparison of data obtained by different fish surveys covering large spatio-temporal scales, necessary in understanding GZ dynamics. It is, thus, mandatory that the methodological guidelines provided are followed without any modification to ensure the utmost quality of the data acquired. 
Survey and Basic trawl information

\begin{tabular}{|c|c|c|c|c|c|c|c|c|c|c|c|c|c|}
\hline Survey & Boat & $\begin{array}{c}\text { Date } \\
\text { (dd/mm/yyyy) }\end{array}$ & $\begin{array}{c}\text { Station } \\
\text { name }\end{array}$ & $\begin{array}{l}\text { Trawl number } \\
\text { (if different) }\end{array}$ & Trawl type & Time & Latitude & Longitude & Duration & $\begin{array}{c}\text { Mean speed } \\
\quad(k t)\end{array}$ & Fishing depth & Water depth (max.) & $\begin{array}{c}\text { Total trawl catch } \\
\text { weight }\end{array}$ \\
\hline
\end{tabular}

Catch information

\begin{tabular}{|c|c|c|c|c|c|c|}
\hline $\begin{array}{c}\text { Date } \\
\text { (dd/mm/yyy) }\end{array}$ & Trawl number & Taxa name & $\begin{array}{c}\text { Taxa weight } \\
\text { (non- } \\
\text { countable } \\
\text { organisms) }\end{array}$ & $\begin{array}{c}\text { Taxa weight } \\
\text { (countable } \\
\text { organisms) }\end{array}$ & $\begin{array}{c}\text { Total taxa weight } \\
\text { (=taxa weight } \\
\text { uncountable+countable) }\end{array}$ & \\
& & & & & \\
\hline
\end{tabular}

Length measurement information

\begin{tabular}{|c|c|c|c|c|}
\hline $\begin{array}{c}\text { Date } \\
(\mathrm{dd} / \mathrm{mm} / \mathrm{yyyy})\end{array}$ & $\begin{array}{c}\text { Trawl } \\
\text { number }\end{array}$ & Taxa name & $\begin{array}{c}\text { Length } \\
\text { class }\end{array}$ & Comments \\
\hline
\end{tabular}

CTD information

\begin{tabular}{|c|c|c|c|c|c|c|}
\hline $\begin{array}{c}\text { Date } \\
(\mathrm{dd} / \mathrm{mm} / \mathrm{yyyy})\end{array}$ & Station name & Time & Depth & Temperature $\left({ }^{\circ} \mathrm{C}\right)$ & Salinity & Fluorescence \\
& & & & & & \\
\hline
\end{tabular}

Table 3. Data required for each trawl for the monitoring of GZ organisms: basic trawl information, biological information and CTD information (when CTD is run for the station) 


\section{Discussion and recommendations}

This trial period took advantage of on-going fishery surveys and returned positive feedback and results. First, it confirmed that it is feasible to collect GZ from the fish trawls examined. Most of the caught GZ were in good enough condition to be identified to phylum, genus or down to species level, without requiring specific expertise in GZ taxonomy onboard. The different GZ taxa found and their representativeness in the total gelatinous catch (in term of biomass and number of individuals) within each type of survey are presented on Figure 4.

\section{GZ taxa contribution to total GZ catch}

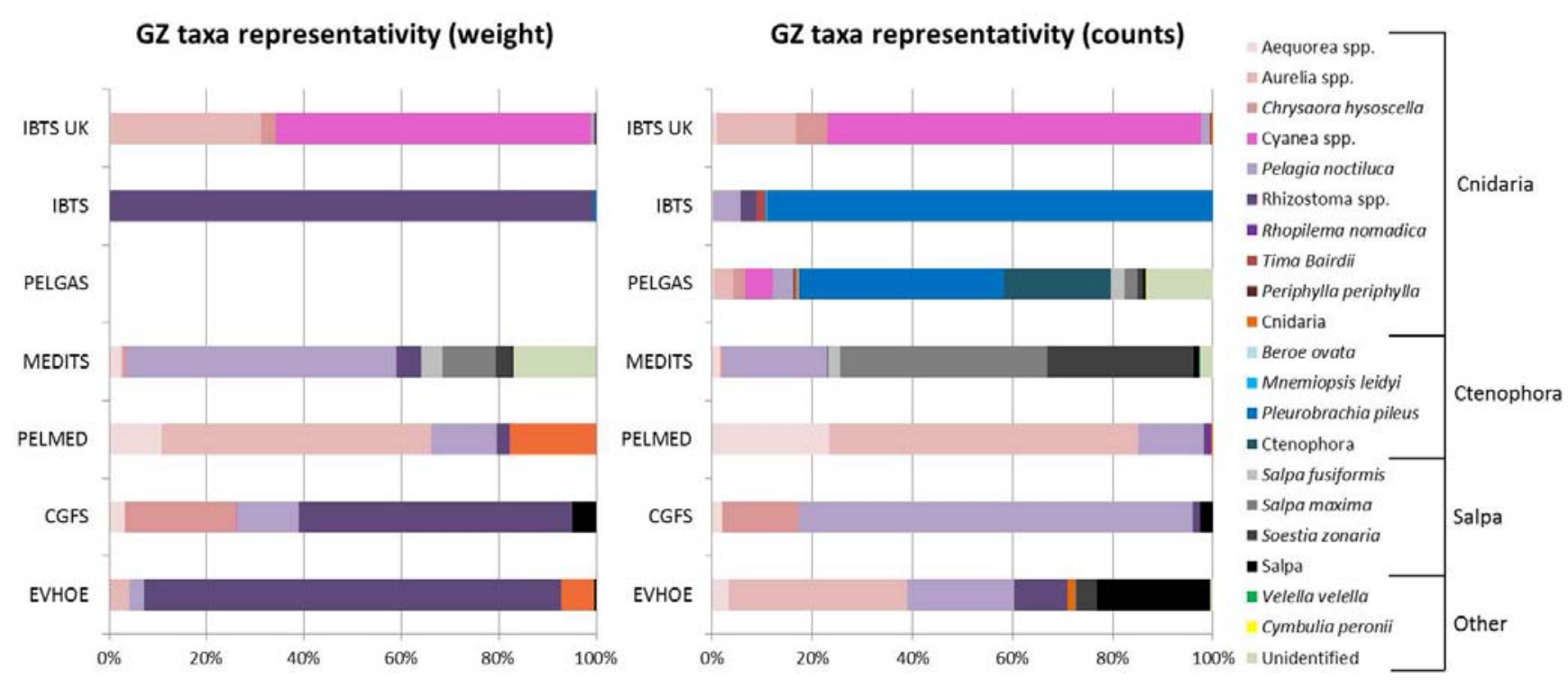

Figure 4. GZ taxa found and contribution of each GZ taxa to the total weight of GZ catch (on the left) and to the total count of GZ individuals (on the right) for the surveys of consideration (see. Fig. 1). The Cnidaria types are shown with colors from pink to brown, small-size Ctenophora species with a blue gradient and Salpa species with a grey gradient. Within the genus Rhizostoma spp. both R. pulmo and R. octopus have been found. Only the surveys where the step-protocol has been applied the same way have been used. GZ weight data for PELGAS are currently not available. These pre-results carry only informative values for GZ taxa presence and trends of representativeness since abundance- and biomass-based densities are not yet available (results are thus not comparable since surveys use different fishing trawls and have different spatio-temporal coverages). 
The protocol has been tested on several surveys covering different spatial and temporal scales, thus, demonstrating the adaptability of fishery survey protocols and staff. The time required to complete the observation of $\mathrm{GZ}$ was found to be reasonable and compatible with the sorting workflow of most fishery surveys. The ease at which it can be added to existing fishery surveys makes this protocol cost- and time-effective. Today the opportunistic use of fishery surveys provides the only large spatio-temporal sampling tool of GZ and so at low cost. New video systems have been developed and seem promising for the monitoring of jellyfish [46], but their cost-effectiveness need to be addressed.

This sampling method has however limitations due to its opportunistic nature and because it was not originally designed to target GZ. The main limitation is related to the fishing gear characteristics (e.g., mesh size, mouth opening, trawling speed, and duration), which results in semi-quantitative rather than quantitative data. During one of the French IBTS survey, MIK net sampling was realized in the same area as the GZ protocol sampling. The diversity as well as the amount of small size GZ were systematically higher in the MIK net (Fig. 5).
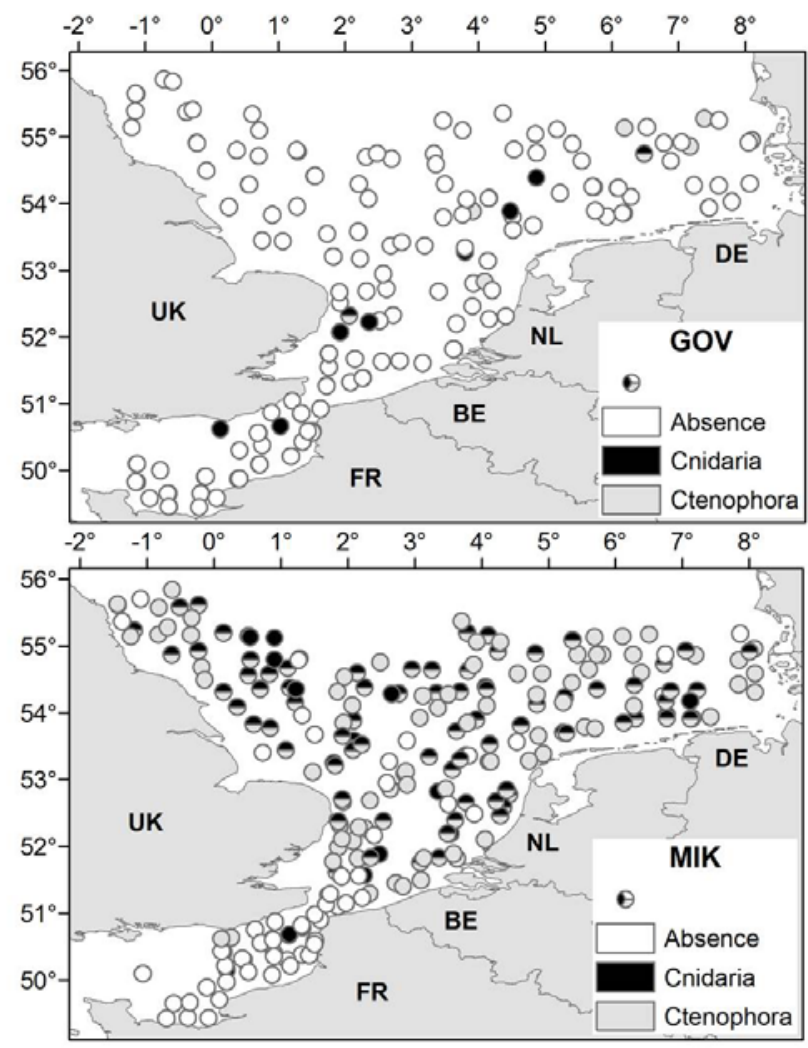

Figure 5. Absence and presence of the two main GZ taxa (Phylum), Cnidaria and Ctenophora, caught with fish trawl (GOV; shown on the top) and with MIK nets (shown below) during the French IBTS fishery survey (2015-2016). 
This difference is mainly related to the high abundance of small size $G Z$ organisms $(<2 \mathrm{~cm})$ such as small ctenophores (e.g. Pleurobrachia pileus), and small jellyfish found exclusively or in higher absolute numbers in the MIK than in the trawls (Fig. 4). This is due to the smaller mesh size of the MIK (5 mm) [17] in comparison to the trawl (minimum mesh size toward the cod-end is $25 \mathrm{~mm}$ among the trawls used in this study). Even though small organisms can be abundant in the trawl, their biomass usually only represents a few percentage of the total GZ catch, and therefore, they should be estimated in a qualitative manner. Indeed, the trawling device may not be adequate for these small and more fragile gelatinous organisms, as they are more likely to pass or to be extruded through the mesh, or to be damaged by the rest of the catch during trawling. However, since very little information exists on the offshore distribution of these small GZ size-classes, data obtained from the trawl remains very valuable in term of presence.

Clearly, a better picture of the GZ community would be obtained with specific nets which should be used in addition to the opportunistic fish trawl sampling when the opportunity arises. MIK nets can filter large volumes of water and can catch dispersed GZ, but they are typically heavy, and deployments are restricted to those from large research vessels. The main advantage of the trawl sampling is its large volume filtering capacity. As an example, the MIK net (for a deployment at 3 knots) samples 10 times less $\left(5600 \mathrm{~m}^{3}\right.$ ) than the GOV trawl net used on the North Sea IBTS survey (see ICES IBTSWG manual for details, [9]). Therefore, the limitations of the opportunistic use of fish trawling, in term of ability to produce reliable quantitative data, are compensated by the large spatio-temporal coverage of the surveys and the large volume filtered by the trawl. The trawl is more suitable for horizontally and vertically dispersed organisms, notably large GZ which are rarely caught in smaller devices [47]. Fish trawling is, thus, currently the most efficient and cost-effective method to collect GZ organisms.

From a long-term monitoring perspective, improvements could be made to this sampling methodology to increase cost-efficiency and the value of the data produced. The initial proposition took advantage of existing fishery surveys and thus did not consider any specific seasonality or sampling areas relevant to GZ monitoring. GZ are known to exhibit large inter- and intra-annual variability, mostly appearing in European temperate waters between spring and late summer [1, 7] (cf. Fig. 3, the highest diversity of GZ species is found in surveys conducted at the end of spring through autumn i.e., PELGAS, PELMED, MEDITS and CGFS). A long-term study (over 50 years) in the Dutch Wadden Sea [7] highlighted no change in the timing of the maximum abundance of scyphomedusae but a significant change in the timing of the first appearance. Although, GZ species have been recorded during this testing in autumn and winter surveys (Fig. 3, CGFS, EVHOE and IBTS surveys), a bespoke monitoring program for GZ should cover the start of spring and early summer to capture the full population dynamics of the GZ. Since this is unlikely to occur, seasonality 
should be recorded by either sentinel sites or, where those do not exist, then through citizen science recording.

A second area of potential improvement is the geographical coverage. In the case of pelagic fishery surveys, stations are selected according to the presence of potential shoal of fish, mainly pre-detected with acoustic devices [48]. Observations from the present trial phase on demersal and pelagic fish surveys suggested that when fish catches are large (total weight), caught GZ biomass tend to be less important. This observation could be explained by competition for food or active avoidance of jellyfish by fish. Fish stock detection by acoustic devices on pelagic surveys may imply that GZ are caught where they are not abundant. The use and improvement of multibeam frequency acoustics systems toward the detection of jellyfish might be a solution to test this hypothesis and potentially adapt the sampling strategy [49].

The morphology, mobility and thus behaviour of GZ in relation to the fishing trawl are different to that of fish and this difference should be considered. Further technical operations should be performed, such as the use of underwater camera attached to the trawl or the testing of different type of trawls (pelagic or demersal, with or without large vertical opening). This would improve the understanding of the trawl net impact on escape and clogging effects, and of the interaction of GZ, as well as fish, with the net at different mesh sizes.

Another point to consider is the calculation of the trawl volume necessary to express GZ abundance. Two main metrics need to be agreed upon by the scientific community to calculate the filtering trawl volume for GZ: the trawl distance and the aperture of the trawl. For the trawl distance, direct distance measurement using flow meter should be favoured but is often unpractical and even impossible to obtain in a standardized fishery survey (the use of flow meter would risk altering the fish catchability). It is therefore calculated indirectly from sampling time and the average speed of the ship. Sampling time for GZ sampling has been considered previously from the start of the trawl deployment to the end of the retrieval phase $[37,50]$, since $G Z$ can be present in the entire water column $[51,52]$ and can be caught during both ascent and descent of the net. However, other fishery technology experts state that trawl duration should be calculated from the beginning to end of the haul, disregarding the shouting and hauling phases. This is due to the fact that the trawl aperture geometry cannot be accurately estimated and may not be effectively fishing for mobile species, particularly when the vessel speed is highly variable (Morandeau F., personal communication). Moreover, considering the beginning to the end of the haul would allow for the same duration use as the one for fish densities calculation. Such duration would be more readily available on most fishery surveys. A clear consensus is still to be found on this issue if a shared international protocol is to be used. Some experimentation should be also conducted to monitor the net during deployment in 
cases when GZ are known to be present in the area since there is a concern they may be advected into the net when the vessel is moving at slow speeds, particularly if currents are strong. This issue can be minimised through visual observations during deployment if $\mathrm{GZ}$ are occurring in surface layers.

Concerning the opening of the trawl, calculation of the effective mouth area (i.e. the level where the mesh size is considered sufficient to catch efficiently the organisms) appears as the most appropriate method $[50,53,54]$ since pelagic target organisms are sampled based on net mesh. It must be kept in mind that a trawl is made of diamond-meshed netting, with graded mesh sizes decreasing towards the cod end (Fig. 6). Each trawl has different characteristics, and thus, design characteristics of the trawl should be clearly provided and noted for each fishery survey where the GZ protocol is operated.

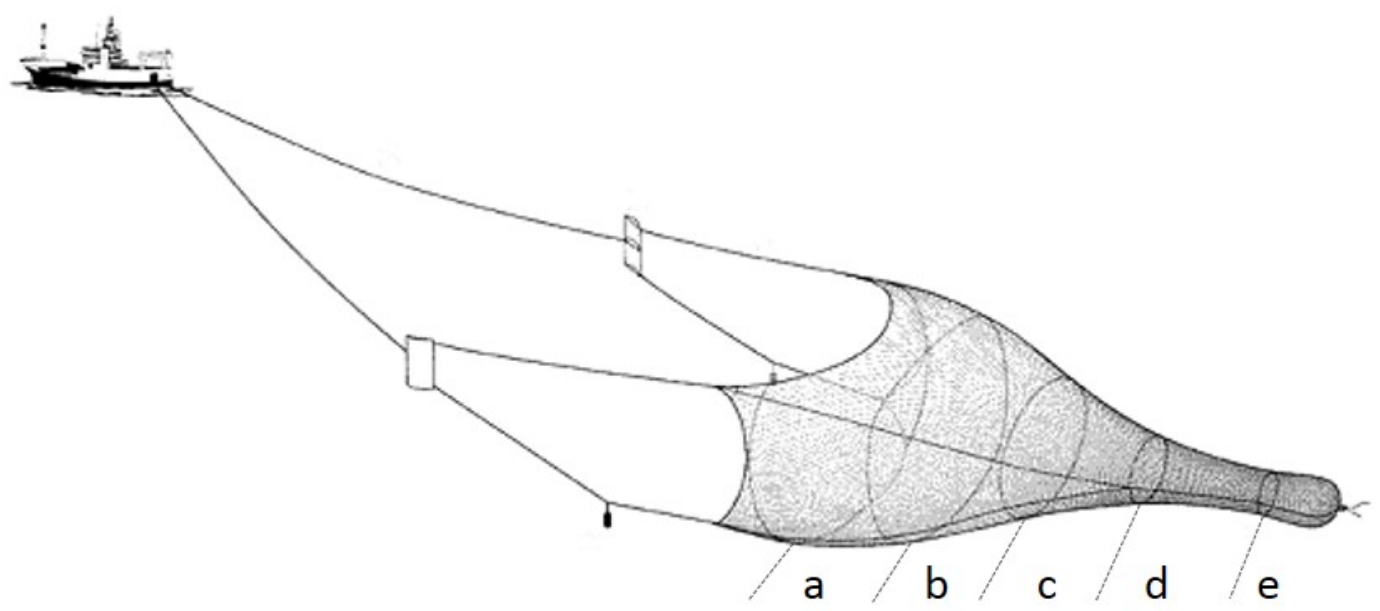

Figure 6. Typical shape of a pelagic fishing trawl made of diamond-meshed netting, with graded mesh sizes decreasing towards the cod end (the different parts (here from $a$ to $e$ ) have different mesh sizes and thus different sampling efficiencies).The size of the aperture should be considered at the level where the mesh size is considered to catch efficiently the organisms.

Effective mouth area is proposed to be calculated according to taxa size [50]. However, average taxa size for specific GZ can be significantly different according to regions and stage of development and is often related to season $[55,56]$. Since measurement of $G Z$ is also available in the proposed standardized protocol, average size of each species could be used instead. Additionally, cut-off mesh size-categories along the trawl could be identified in order to select the most appropriate or likely effective trawl mouth aperture. Such approach would however ignore tentacles' length and their tangling effect with the net, requiring potential adaptation when considering GZ organisms with long tentacles. Moreover, it also ignores the channeling current effect that tends to lead passive organisms toward the cod-end. In contrast, 
the reality of fish actively escaping the net, by forcefully swimming through the stretched mesh, is not routinely accounted for in fishery surveys when expressing density. This point should find a clear consensus within the scientific community to ensure data reliability and comparison between surveys.

One important point highlighted here is the lack of consensus within the scientific community on which unit should be used to express GZ abundance. In the literature, several units are reported wet weight biomass per surface area (WW kg km${ }^{-2}$ ) [48], number of individual per surface area or volume ( $\mathrm{n}$ $\mathrm{km}^{-2}$ or $\mathrm{nm}^{-3}$ ) $[53,14,17,31]$, weight proportion of total catch (\%) [50], or median abundance per hour of trawl $\left(\mathrm{n} \mathrm{h}^{-1}\right)$ [57]. In most of those studies, these units are often derived from more or less complex analytical and statistical processes (i.e. standardization, scaling factor consideration) to account for the spatio-temporal span and patchiness of GZ and mostly to fit the purpose and the hypotheses of the study $[47,17,37,7]$. A common standardized calculation should be established at the earliest stage of any future monitoring program. It will enable data comparisons between surveys and allow efficient future management in marine regions shared between member states. It is recommended to count the number of GZ organisms as well to measure their wet weight biomass per surface area or per volume. Indeed, depending on the type of GZ organisms, counts or biomass might lead to different results (for example in the case of damaged salps a good estimate of abundance can be attained while total biomass will be underestimated).

It is fundamental that routine monitoring programs address management objectives and these aims should be integrated in the design of the monitoring from the start. Monitoring programs should also allow cross-comparison of data and assessment at different spatio-temporal scales. The use of different methodologies between countries for instance, will prevent cross-comparison of data and hinder the full understanding and management of a biological resource whose behaviour is not dependent on administrative limits [58]. As mentioned earlier, there are few cost-effective monitoring programs for $\mathrm{GZ}$ and the recent plea for increasing jellyfish monitoring [8] showed that none exists in Europe. The most comprehensive EU marine environmental legislation, the Marine Strategy Framework Directive, demands an ecosystem approach to environmental management. However, as assessments are largely based on existing data sources, gaps exist for less studied organisms such as GZ.

The present protocol testing has demonstrated that economic resources and operational difficulties of implementation are no longer valid arguments for the absence of monitoring programs dedicated to GZ. The French and English trials were run with very low budget over several years, only requiring negligible consumables, travelling allowances and limited training for the staff operating on board the fishery surveys (protocol implementation and identification training). These trials resulted in the successful 
implementation of this observation protocol in the French MSFD monitoring program that will hopefully inspire other EU coastal Member States. One of the biggest challenges during the testing phase was to convince fisheries scientists of the usefulness and relevance of GZ monitoring based on trawl surveys.

As the number of observations increases and large scale or long-term data sets become available, there is hope for increased scientific interest and understanding of GZ organisms. Brodeur et al. [8] demonstrated that the best scientific advances in understanding GZ dynamics have been made thanks to fishery surveys. The last obstacle of such monitoring is to raise awareness of managers and decision makers that the implementation of an ecosystem approach requires the consideration of GZ. The lack of data on those organisms has prevented the development of dedicated indicators within the MSFD framework so far [59], and may result in the introduction of biases in the developed food-web indicators. Hopefully, the preliminary results obtained applying the present protocol, when expressed as densities, will constitute a base to develop potential GZ indicators and will be useful to understand and monitor GZ dynamics.

At a time when there is still flexibility for improvements of MSFD monitoring programs in Europe, the call for the monitoring of GZ should be taken seriously. Indeed, increases of human activities and development of artificial structure in coastal areas providing habitat for the benthic stage of many jellyfish $[60,61,19]$, will potentially increase the interactions with humans $[1,62]$. To anticipate future problems, cost-efficient monitoring programs must be implemented urgently and be accompanied by parallel scientific studies on GZ dynamics and role in the marine food-webs.

\section{Acknowledgments}

We acknowledge the IFREMER staff that participated in the gelatinous zooplankton sorting during the French fisheries surveys and helped improved the protocol, especially Patrick Lespagnol, Laurence Pennors, Michèle Salaun, Claire Saraux, Louisa Metral, Angélique Jaraud, Jean-Hervé Bourdeix and Jérôme Baudrier. We are also thankful to Guillaume Marchessaux and Julien Richard for their voluntary work. Fabien Morandeau is acknowledged for his useful expertise on fishing trawl technology. Anaïs Aubert received funding from the French Ministry of Environment, Energy, and the Sea (MEEM), the French National Centre for Scientific Research (CNRS-INEE) and the French National Museum of Natural History (MNHN). Elvire Antajan and Sandrine Vaz received funding from the French Ministry of Environment, Energy, and the Sea (MEEM) as part of the MSFD implementation framework. CPL acknowledges funding by the EU FP7 project DEVOTES (grant agreement no. 308392). 
References

[1] Boero F., Review of Jellyfish Blooms in the Mediterranean and Black Sea. Studies and Reviews. General Fisheries Commission for the Mediterranean, 92, 2013, FAO; Rome, 53.

[2] Kim D.-H., Seo J.-N., Yoon W.-D., Suh, Y.-S., Estimating the economic damage caused by jellyfish to fisheries in Korea. Fish. Sci. 78, 2012, 1147-1152, http://dx.doi.org/10.1007/s12562-012-0533-1.

[3] Kontogianni A. D., Emmanouilides C. J., The cost of a gelatinous future and loss of critical habitats in the Mediterranean. ICES J. Mar. Sci. 4 (1), 2014, 853-856, https://doi.org/10.1093/icesjms/fst194

[4] De Donno A., Idolo A., Bagordo F., Grassi T., Leomanni A., Serio F., Guido M., et al., Impact of stinging jellyfish proliferations along south Italian coasts: human health hazards, treatment and social costs, Int. J. Environ. Res. Public Health 11, 2014, 2488-2503.

[5] Smith B.E., Ford M.D., Link J.S., Bloom or burst: synchrony in jellyfish abundance, fish consumption, benthic scavenger abundance, and environmental drivers across a continental shelf, Fish. Oceanogr. 25 (5), 2016, 500-514.

[6] Boero F., Bouillon J., Gravili C., Miglietta M. P., Parsons T., Piraino S., Gelatinous plankton: Irregularities rule the world (sometimes), Mar. Ecol. Prog. Ser. 356, 2008, 299-310.

[7] Van Walraven L., Langenberg V.T., Dapper R., Witte J. IJ., Zuur A. F., Van Der Veer H.W., Long-term patterns in 50 years of scyphomedusae catches in the western Dutch Wadden Sea in relation to climate change and eutrophication, J. Plankton. Res. 37 (1), 2015, 151-167, https://doi.org/10.1093/plankt/fbu088

[8] Brodeur R.D., Link J.S., Smith B.E., Ford M.D., Kobayashi D.R., Jones T.T., Ecological and Economic Consequences of Ignoring Jellyfish: a Plea for Increased Monitoring of Ecosystems, Fisheries 41 (11), 630-637, DOI:10.1080/03632415.2016.1232964.

[9] ICES, Manual for the Midwater Ring Net sampling during IBTS Q1. Series of ICES Survey Protocols SISP 2MIK 2., 2013, p. Available 18, at: (https://www.ices.dk/sites/pub/Publication\%20Reports/ICES\%20Survey\%20Protocols\%20(SISP)/SISP\% 202\%20MIK2.pdf). 
[10] Lilley M. K., Berline L., Ferraris M., Elineau A., Cuvilliers P., Stemmann L., Lombard F., Has the biomass of jellyfish already surpassed small pelagic fish in the NW Mediterranean Sea? Results from an intense spatiotemporal survey during 2011-2014 and comparison with the long-term trend. ICES CM 2014/3064 A:02, 2014.

[11] Condon R. H., Graham W. M., Duarte C. M., Pitt K. A., Lucas C. H., Haddock S. H. D., Sutherland K. R., et al., Questioning the rise of gelatinous zooplankton in the World's Oceans, BioScience 62, 2012, 160169, (http://bioscience.oxfordjournals.org/content/62/2/160.abstract).

[12] Hamilton G., The secret lives of jellyfish, Nature 531, 2016, 5-7, (http://www.nature.com/polopoly_fs/1.19613!/menu/main/topColumns/topLeftColumn/pdf/531432 a.pdf).

[13] Purcell J. E., Arai M. N., Interactions of pelagic cnidarians and ctenophores with fish: a review, Hydrobiologia 451, 2001, 27-44, http://dx.doi.org/10.1023/A:1011883905394.

[14] Lynam C. P., Hay S. J., Brierley A. S., Interannual variability in abundance of North Sea jellyfish and links to the North Atlantic Oscillation, Limnol. Oceanogr. 49, 2004, 637-643.

[15] Lynam C. P., Heath M. R., Hay S. J., Brierley, A. S., Evidence for impacts by jellyfish on North Sea herring recruitment. Mar. Ecol. Prog. Ser. 298, 2005, 157-167.

[16] Schneider G., Behrend G., Top-down control in a neritic plankton system by Aurelia aurita medusae a summary, Ophelia 48, 1998, 71-82, http://dx.doi.org/10.1080/00785236.1998.10428677.

[17] Lynam C., Lilley M., Bastian T., Doyle T. K., Beggs S. E., Hay G.C., Have jellyfish in the Irish Sea benefited from climate change and overfishing? Global Change Biol. 17, 2011, 767-782, (http://doi.wiley.com/10.1111/j.1365-2486.2010.02352.x).

[18] Brodeur R. D., Suchman C. L., Reese D. C., Miller T. W., Daly E., Spatial overlap and trophic interactions between pelagic fish and large jellyfish in the northern California Current, Mar. Biol. 154, 2008, 649659.

[19] Richardson A. J., Bakun A., Hays G. C., Gibbons M. J., The jellyfish joyride: causes, consequences and management responses to a more gelatinous future, Trends Ecol. Evol. 24, 2009, 312-322.

[20] Lynam C.P., Gibbons M.J., Axelsen B.E., Sparks C.A.J., Coetzee J., Heywood B.G., Brierley A.S., Jellyfish 
overtake fish in a heavily fished ecosystem. Curr. Biol. 16, 2006, 492-493.

[21] Oguz T., Gilbert D., Abrupt transitions of the top-down controlled Black Sea pelagic ecosystem during 1960-2000: evidence for regime-shifts under strong fishery exploitation and nutrient enrichment modulated by climate-induced variations, Deep Sea Res. I 54 (2), 2007, 220-242, https://doi.org/10.1016/j.dsr.2006.09.010.

[22] Graham W. M., Gelcich S., Robinson K. L., Duarte C. M., Brotz L., Purcell J. E., Madin L. P., Mianzan H., Sutherland K. R., Uye S.-i., Pitt K. A., Lucas C. H., Bøgeberg M., Brodeur R. D., Condon R. H., Linking human well-being and jellyfish: ecosystem services, impacts, and societal responses. Front. Ecol. Environ. 12, 2014, 515-523, doi:10.1890/130298.

[23] Duarte C. M., Pitt K. A., Lucas, C. H., Purcell J. E., Uye S.-i., Robinson K., Brotz L., Decker M. B., Sutherland K. R., Malej A., Madin L., Mianzan H., Gili J.-M., Fuentes V., Atienza D., Pagés F., Breitburg D., Malek J., Graham W. M., Condon R. H., Is global ocean sprawl a cause of jellyfish blooms? Front. Ecol. Environ. 11, 2013, 91-97, doi:10.1890/110246.

[24] Patwa A., Thiéry A., Lombard F., Lilley M. K.S., Boisset C., Bramard J.F., Bottero J.Y., Barthélémy P., Accumulation of nanoparticles in "jellyfish" mucus: a bio-inspired route to decontamination of nanowaste. Sci. Rep. 5, 2015, 11387, doi:10.1038/srep11387.

[25] Cardona L., Álvarez de Quevedo I., Borrell A., Aguilar A., Massive consumption of gelatinous plankton by Mediterranean apex predators, PloS one 7, 2015, e31329, http://dx.doi.org/10.1371/journal.pone.0031329 (Public Library of Science).

[26] Smith B. E., Ford M. D., Link J. S., Bloom or bust: synchrony in jellyfish abundance, fish consumption, benthic scavenger abundance, and environmental drivers across a continental shelf, Fish. Oceanogr. 25, 2016, 500-514, doi:10.1111/fog.12168.

[27] Henschke N., Everett J.D., Richardson A.J., Suthers I.M., Rethinking the role of salps in the Ocean, Trends Ecol. Evol. 31 (9), 2016, 720-733, https://doi.org/10.1016/j.tree.2016.06.007.

[28] Sweetman A. K., Chapman A., First assessment of flux rates of jellyfish carcasses (jelly-falls) to the benthos reveals the importance of gelatinous material for biological C-cycling in jellyfish-dominated ecosystems, Front. Mar. Sci. 2 (47), 2015, doi: 10.3389/fmars.2015.00047.

[29] European Commission, Marine Strategy Framework Directive 2008/56/EC, European Commission, 
2008.

[30] Ecosystem Assessment Program, 2012, Ecosystem Status Report for the Northeast Shelf Large Marine Ecosystem - 2011. US Dept Commer, Northeast Fish Sci Cent Ref Doc. 12-07; 32 p.

[31] Davies J., Baxter J., Bradley M., Connor D., Khan J., Murray E., Sanderson W., Turnbull C., Vincent M., Marine Monitoring Handbook, ISBN 185716550 0, 2001, p. 405.

[32] Rogers S. I., Greenaway B., A UK perspective on the development of marine ecosystem indicators, Mar. Pollut. Bull. 50, 2005, 9-19, (http://linkinghub.elsevier.com/retrieve/pii/S0025326X04003637).

[33] Van Tatenhove J., Raakjaer J., Van Leeuwen J., Van Hoof L., Regional cooperation for European seas: Governance models in support of the implementation of the MSFD, Mar. Policy 50 (Part B), 2014, 364-372, (http://www.sciencedirect.com/science/article/pii/S0308597X14000700).

[34] Sanz-Martin M., Pitt K.A., Condon R.H., Lucas C.H., Novaes de Santana C., Duarte C.M., Flawed citation practices facilitate the unsubstantiated perception of a global trend toward increased jellyfish blooms, Glob. Ecol. Biog. 25, 2016, 1039-1049, doi:10.1111/geb.12474.

[35] ICES, Report of the International Bottom Trawl Survey Working Group (IBTSWG), 8-12 April 2013, Lisbon, Portugal, CIEM / ICES, Ref. ICES CM 2013/SSGESST: 10, p. 278. (http://archimer.ifremer.fr/doc/00190/30112/).

[36] Bastian T., Haberlin D., Purcell J. E., Hays G. C., Davenport J., McAllen R., Doyle T. K., Large-scale sampling reveals the spatio-temporal distributions of the jellyfish Aurelia aurita and Cyanea capillata in the Irish Sea, Mar.Biol. 158, 2011, 2639-2652, http://dx.doi.org/10.1007/s00227-011-1762-z.

[37] Robinson K. L., Graham W. M., Long-term change in the abundances of northern Gulf of Mexico scyphomedusae Chrysaora spp. and Aurelia spp. with links to climate variability, Limnol. Oceanogr. 58, 2013, 235-253.

[38] Spencer M.L., Stoner A.W., Ryer C.H., Munk J.E., A towed camera sled for estimating abundance of juvenile flatfishes and habitat characteristics: Comparison with beam trawl and divers, Estuar. Coast Shelf Sci. 64 (2-3), 2005, 497-503.

[39] Verin Y., IBTS International Bottom Trawl Survey (IBTS), 1992, http://dx.doi.org/10.18142/17.

[40] Coppin F., Travers-trolet M., CGFS: Channel Ground Fish Survey, 1989, http://dx.doi.org/10.18142/11. 
[41] Mahe J.C. , EVHOE EValuation Halieutique de l'Ouest de l'Europe, 1987, http://dx.doi.org/10.18142/8.

[42] Doray M., Duhamel E., Huret M., Petitgas P., Masse J., PELGAS, 2002, http://dx.doi.org/10.18142/18.

[43] Bertrand J., MEDITS, 1994, http://dx.doi.org/10.18142/7.

[44] Bourdeix J.H., Saraux C., PELMED - PELAGIQUES MEDITERRANÉE, 1985, http://dx.doi.org/10.18142/19.

[45] Aubert A., Thibault D., Guide DCSMM d'aide à la détermination des principaux types/espèces de macro- et mégazooplancton gélatineux. Programme de Surveillance DCSMM, 2017, 70p., http://doi.org/10.13155/50398.

[46] Corgnati L., Marini S., Mazzei L., Ottaviani E., Aliani S., Conversi A., Griffa A., Looking inside the Ocean: toward an autonomous imaging system for monitoring gelatinous zooplankton, Sensors 16 (12), 2016, 2124, doi:10.3390/s16122124.

[47] Magome S., Yamashita T., Kohama T. Kaneda A., Hayami Y., Takahashi S., Takeoka H., Jellyfish patch formation investigated by aerial photography and drifter experiment, J. Oceanogr. 63, 2007, 761, doi:10.1007/s10872-007-0065-y.

[48] Eriksen E., Do scyphozoan jellyfish limit the habitat of pelagic species in the Barents Sea during the late feeding period? ICES J. Mar. Sci. 73, 2, 2015, 217-226, doi:10.093/icesjms/fsv13.

[49] Brierley A., Boyer D., Axelsen B., Lynam C., Sparks C., Boyer H., Gibbons, M., Towards the acoustic estimation of jellyfish abundance. Mar. Ecol. Prog. Ser. 295, 2005, 105-111.

[50] Suchman C. L., Brodeur R. D., Abundance and distribution of large medusae in surface waters of the northern California Current, Deep Sea Res. I/ 52 (1), 2005, 51-72.

[51] Costello J.H., Mianzan H.W., Sampling field distribution of Mnemiopsis leidyi (Ctenophora, Lobata): planktonic or benthic methods? J. Plank. Res. 25, 2003, 455-459.

[52] Hays G. C., Bastian T., Doyle T. K., Fossette S., Gleiss A. C., Gravenor M. B., Hobson V.J., Humphries N.E., Lilley M.K.S., Pade N.G., Sims D. W., High activity and Lévy searches: jellyfish can search the water column like fish, Proc. R. Soc. B. 279 (1728), 2012, 465-473.

[53] Brodeur R.D., Barcelo C., Robinson K.L., Daly E.A., Ruzicka J.J., Spatial overlap between forage fishes and the large medusa Chrysaora fuscescens in the northern California Current region, Mar. Ecol. Prog. Ser. 510, 2014, 167-181. 
[54] Suchman C. L., Brodeur R. D., Daly E., Emmett R. L., Large medusae in surface waters of the Northern California Current: Variability in relation to environmental conditions, Hydrobiol 690, 2012, 113-125.

[55] Malej A., Malej M., Population dynamics of the jellyfish Pelagia noctiluca (Forsskål, 1775), Marine Eutrophication and Populations Dynamics, ISBN 87-85215-19-8, 1992.

[56] Purcell J.E., Uye S., Lo W-T., Anthropogenic causes of jellyfish blooms and their direct consequences for humans: a review, Mar. Ecol. Prog. Ser. 350, 2007, 153-174, https://doi.org/10.3354/meps07093.

[57] Hay S.J., Hislop J.R.G., Shanks A.M., North Sea Scyphomedusae; summer distribution, estimated biomass and significance particularly for 0-group Gadoid fish, Neth. J. Sea Res. 25 (1), 1990, 113-130, http://dx.doi.org/10.1016/0077-7579(90)90013-7 (ISSN 0077-7579).

[58] Patrício J., Little S., Mazik K., Papadopoulou K. N., Smith C. J., Teixeira H., Hoffmann H., Uyarra M.C., Solaun O., Zenetos A., Kaboglu G., Kryvenko O., Churilova T., Moncheva S., Bucas M., Borja A., Elliot M., European marine biodiversity monitoring networks: strengths, weaknesses, opportunities and threats, Front. Mar. Sci. 3 (161), 2016, 161, https://doi.org/10.3389/fmars.2016.00161.

[59] McQuatters-Gollop A., Johns D. G., Bresnan E., Skinner J., Rombouts I., Stern R., Aubert A., Johansen M., Bedford J., Knights, A., From microscope to management: The critical value of plankton taxonomy to marine policy and biodiversity conservation, Mar. Pol. 83, 2017, 1-10, https://doi.org/10.1016/j.marpol.2017.05.022.

[60] Duarte C. M., Pitt K. A., Lucas C. H., Purcell J. E., Uye S., Robinson K., Brotz L., et al., Is global ocean sprawl a cause of jellyfish blooms? Front. Ecol. Envir. 11, 2013, 91-97, http://doi.wiley.com/10.1890/110246.

[61] Holst S., Jarms G., Substrate choice and settlement preferences of planula larvae of five Scyphozoa (Cnidaria) from German Bight, North Sea, Mar. Biol. 151, 2006, 863-871, http://dx.doi.org/10.1007/s00227-006-0530-y.

[62] Brotz L., Cheung W. W. L., Kleisner K., Pakhomov E., Pauly D., Increasing jellyfish populations: trends in Large Marine Ecosystems, Hydrobiol. 690, 2012, 3-20, http://dx.doi.org/10.1007/s10750-012-1039-7. 